\title{
Technical Note: Approaches and software tools to investigate the impact of ocean acidification
}

\author{
J.-P. Gattuso ${ }^{1,2}$ and H. Lavigne ${ }^{1,2}$ \\ ${ }^{1}$ CNRS-INSU, Laboratoire d'Océanographie de Villefranche, BP 28, 06234 Villefranche-sur-Mer Cedex, France \\ ${ }^{2}$ Université Pierre et Marie Curie-Paris 6, Observatoire Océanologique de Villefranche, \\ 06230 Villefranche-sur-Mer Cedex, France
}

Received: 20 February 2009 - Published in Biogeosciences Discuss.: 21 April 2009

Revised: 9 September 2009 - Accepted: 19 September 2009 - Published: 8 October 2009

\begin{abstract}
Although future changes in the seawater carbonate chemistry are well constrained, their impact on marine organisms and ecosystems remains poorly known. The biological response to ocean acidification is a recent field of research as most purposeful experiments have only been carried out in the late 1990s. The potentially dire consequences of ocean acidification attract scientists and students with a limited knowledge of the carbonate chemistry and its experimental manipulation. Hence, some guidelines on carbonate chemistry manipulations may be helpful for the growing ocean acidification community to maintain comparability. Perturbation experiments are one of the key approaches used to investigate the biological response to elevated $\mathrm{pCO}_{2}$. They are based on measurements of physiological or metabolic processes in organisms and communities exposed to seawater with normal or altered carbonate chemistry. Seawater chemistry can be manipulated in different ways depending on the facilities available and on the question being addressed. The goal of this paper is (1) to examine the benefits and drawbacks of various manipulation techniques and (2) to describe a new version of the $\mathrm{R}$ software package seacarb which includes new functions aimed at assisting the design of ocean acidification perturbation experiments. Three approaches closely mimic the on-going and future changes in the seawater carbonate chemistry: gas bubbling, addition of high- $\mathrm{CO}_{2}$ seawater as well as combined additions of acid and bicarbonate and/or carbonate.
\end{abstract}

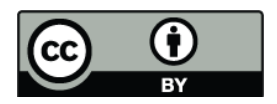

Correspondence to: J.-P. Gattuso (gattuso@obs-vlfr.fr)

\section{Introduction}

Ocean acidification refers to the on-going decrease in ocean $\mathrm{pH}$ as a result of the uptake of anthropogenic carbon dioxide $\left(\mathrm{CO}_{2}\right)$ in the ocean. The partial pressure of $\mathrm{CO}_{2}\left(\mathrm{pCO}_{2}\right)$ increases in the atmosphere due to anthropogenic inputs. It has increased by about $40 \%$ ( 267 to $384 \mu$ atm) since the beginning of the industrial revolution leading to changes in the Earth's climate and in the functioning of terrestrial ecosystems. The world's oceans currently absorb on average about one metric ton of $\mathrm{CO}_{2}$ produced by each person every year. It is estimated that the surface waters of the oceans have taken up $118 \mathrm{Pg} \mathrm{C}$, or about $25 \%$ of the carbon generated by human activities since 1800 (Sabine et al., 2004). The increase of $\mathrm{pCO}_{2}$ profoundly affects the seawater carbonate system (Table 1). It increases the concentrations of bicarbonate and dissolved inorganic carbon, and lowers $\mathrm{pH}$, the concentration of carbonate ions $\left(\mathrm{CO}_{3}^{2-}\right)$ and the saturation state of the major shell-forming carbonate minerals:

$$
\mathrm{CO}_{2}+\mathrm{CO}_{3}^{2-}+\mathrm{H}_{2} \mathrm{O} \rightarrow 2 \mathrm{HCO}_{3}^{-}
$$

Surface ocean $\mathrm{pH}$ is estimated to have decreased from approximately 8.20 to 8.07 between preindustrial time and the 1990s and may reach 7.79 in 2100 (Table 1). The expression "ocean acidification" refers to the decrease in $\mathrm{pH}$ but does not imply that the $\mathrm{pH}$ of surface ocean waters will become acidic (below 7.0) any time soon.

Although the chemistry of ocean acidification is very well known, the associated impacts on marine organisms and ecosystems remain poorly known. The impact of low $\mathrm{pH}$ on marine organisms started to be investigated several decades ago (e.g. Bouxin, 1926), yet research into the biological response to ocean acidification is still in its infancy: the first

Published by Copernicus Publications on behalf of the European Geosciences Union. 
Table 1. Changes in the carbonate chemistry of surface seawater from the Last Glacial Maximum (LGM; 18 ky BP) to 2100 . Total alkalinity, $\mathrm{CO}_{2}$ partial pressure $\left(\mathrm{pCO}_{2}\right)$, salinity and temperature were fixed and used to derive all other parameters using the seacarb software (Lavigne et al., 2008) and the dissociation constant of carbonic acid of Lueker et al. (2000). It is assumed that the ocean and atmosphere are in equilibrium with respect to $\mathrm{CO}_{2}$. Values of temperature, salinity, total alkalinity and total phosphate in 1766,2007 and 2100 are from Plattner et al. (2001) prescribing historical $\mathrm{CO}_{2}$ records and non- $\mathrm{CO}_{2}$ radiative forcing from 1766 to 1990 and using the A2 IPCC SRES emissions scenario (Nakićenović and Swart, 2000) thereafter. Temperature during the LGM was set $1.9^{\circ} \mathrm{C}$ colder than in 2007 (MARGO Project Members, 2009). The LGM salinity was set 1.07 higher than during pre-industrial time (Paul and Schäfer-Neth, 2003). Total alkalinity in the LGM was scaled to salinity while the total phosphate concentration was assumed to be the same as in 1766 . pCO 2 in 1766 and 2100 are from Plattner et al. (2001), while values in the LGM and 2007 are from Petit et al. (2001) and Keeling et al. (2008), respectively. The concentration of total silicate is assumed to have remained constant from the LGM to 2100. It was calculated using the gridded data reported by Garcia et al. (2006) between 0 and $10 \mathrm{~m}$ and weighing the averages using the surface area of each grid cell. pH is expressed on the total scale.

\begin{tabular}{lrrrrr}
\hline Parameter & Unit & LGM & 1766 & 2007 & 2100 \\
\hline Temperature & ${ }^{\circ} \mathrm{C}$ & 17.2 & 18.3 & 18.9 & 21.4 \\
Salinity & - & 36 & 34.9 & 34.9 & 34.7 \\
Total phosphate & $10^{-6} \mathrm{~mol} \mathrm{~kg}^{-1}$ & 0.66 & 0.66 & 0.63 & 0.55 \\
Total silicate & $10^{-6} \mathrm{~mol} \mathrm{~kg}^{-1}$ & 7.35 & 7.35 & 7.35 & 7.35 \\
Total alkalinity & $10^{-6} \mathrm{~mol} \mathrm{~kg}^{-1}$ & 2399 & 2326 & 2325 & 2310 \\
$\mathrm{CO}_{2}$ partial pressure (seawater) & $\mu \mathrm{\mu atm}$ & 180 & 267 & 384 & 793 \\
{$\left[\mathrm{CO}_{2}\right]$} & $10^{-6} \mathrm{~mol} \mathrm{~kg}^{-1}$ & 6.26 & 9.05 & 12.8 & 24.7 \\
{$\left[\mathrm{HCO}_{3}^{-}\right]$} & $10^{-6} \mathrm{~mol} \mathrm{~kg}^{-1}$ & 1660 & 1754 & 1865 & 2020 \\
{$\left[\mathrm{CO}_{3}^{2-}\right]$} & $10^{-6} \mathrm{~mol} \mathrm{~kg}^{-1}$ & 299 & 231 & 186 & 118 \\
Dissolved inorganic carbon & $10^{-6} \mathrm{~mol} \mathrm{~kg}^{-1}$ & 1966 & 1994 & 2064 & 2162 \\
$\mathrm{pH}_{T}$ & - & 8.33 & 8.20 & 8.07 & 7.79 \\
{$\left[\mathrm{H}^{+}\right]$} & $10^{-9} \mathrm{~mol} \mathrm{~kg}^{-1}$ & 4.589 & 6.379 & 8.600 & 16.13 \\
Calcite saturation & - & 7.1 & 5.5 & 4.5 & 2.8 \\
Aragonite saturation & - & 4.6 & 3.6 & 2.9 & 1.8 \\
\hline
\end{tabular}

purposeful manipulative experiment was carried out only in the 1980s (Agegian, 1985) and others began only in the late 1990s. The potentially dire consequences of ocean acidification have attracted the interest of scientists and students with a limited knowledge of the carbonate chemistry and its experimental manipulation. Hence, some guidelines on carbonate chemistry and its manipulation may be helpful for the growing ocean acidification community in order to ensure that the most adequate approaches are used and that results and subsequent analyses are comparable. The need to standardize measurement of parameters of the carbonate system has been identified (Kleypas et al., 2006), a gap which was recently filled (Dickson et al., 2007). Perturbation experiments are one of the key approaches used to investigate the biological response to elevated $\mathrm{pCO}_{2}$. They are based on measurements of physiological or metabolic processes in organisms and communities exposed to seawater with normal or altered chemistry. Seawater chemistry can be manipulated using different ways depending on the facilities available and on the question being addressed. Langdon (2000) summarized the state-of-the-art techniques used with reef builders. Here we examine the benefits and drawbacks of current methods and provide a software package to assist the design of perturbation experiments.

\section{Method}

Detailed information on the carbonate chemistry, including the merit of units and scales, as well as on the measurement methods can be found in Dickson et al. (2007), Zeebe and Wolf-Gladrow (2001) and in the Guide for Best Practices in Ocean Acidification Research and Data Reporting in preparation (see http://www.epoca-project.eu/index.php/ Best-Practices-Guide/).

The R package seacarb was used to calculate the carbonate chemistry parameters. $R$ is a free cross-platform language and environment for statistical computing and graphics (R Development Core Team, 2008). The previous version, seacarb 1.2.3 (Proye and Gattuso, 2003) is superseded by the recently released version 2.0 (Lavigne et al., 2008). The new version has been updated in order to be fully consistent with the most recent guidelines to best practices for ocean $\mathrm{CO}_{2}$ measurements (Dickson et al., 2007). All equations are solved analytically except when total alkalinity is one of the two input parameters of the carbonate system that are required. In that case, the concentration of $\mathrm{H}^{+}$or dissolved inorganic carbon are solved numerically using the $\mathrm{R}$ function uniroot. Five new functions have been added to seacarb 2.0 to assist the design of ocean acidification perturbation experiments. The syntax of these commands is briefly 
described in Appendices A1 to A5. Additional information is available in the help files of the seacarb package.

\section{Main approaches}

The seawater chemistry can be manipulated in various ways in order to alter parameters of the carbonate system. The following sections examine the five techniques that are most useful in the context of ocean acidification. Calculations were carried out using the first and second dissociation constants of carbonic acid given by Lueker et al. (2000). In systems open to the atmosphere, it is assumed that the seawater and atmosphere are in equilibrium with respect to $\mathrm{CO}_{2}$. It must be pointed out that the methods described below enable to set the carbonate chemistry at the beginning of a perturbation experiment. However, initial values can be altered by biological (e.g. photosynthesis, respiration and calcification) and physical processes (e.g. air-seawater exchange of $\mathrm{CO}_{2}$ and temperature changes), which must also be taken into account in the experimental design.

\subsection{Gas bubbling}

Bubbling seawater with gases is an efficient way to manipulate its carbonate chemistry. The seacarb function pgas estimates the changes in the carbonate chemistry resulting from changes in $\mathrm{pCO}_{2}$ generated by bubbling gases.

Example: seawater with a $\mathrm{pCO}_{2}$ of $384 \mu \mathrm{atm}$ and total alkalinity (TA) of $2325 \mu \mathrm{mol} \mathrm{kg}{ }^{-1}$ is bubbled with a mixture of $\mathrm{CO}_{2}$ and air with a $\mathrm{pCO}_{2}$ of $793 \mu \mathrm{atm}$. Salinity is 34.9, temperature is $18.9^{\circ} \mathrm{C}$ and calculations are made for surface waters. The command needed is:

pgas(flag $=24, \operatorname{var} 1=384$, var2 $=2325 \mathrm{e}-6, \mathrm{pCO} 2 \mathrm{~g}=793$, $\mathrm{S}=34.9, \mathrm{~T}=18.9$ )

This approach exactly reproduces the changes of all parameters of the carbonate system expected in the year 2100 (Fig. 1 and Table 2). Smith and Roth (1979) is perhaps the first publication which manipulated the carbonate chemistry via gas bubbling within a range compatible with that of the on-going ocean acidification.

Two techniques have been used in the context of ocean acidification: $\mathrm{pH}$-stat and bubbling with premixed gases. In $\mathrm{pH}$-stat systems, $\mathrm{pH}$ is monitored continuously and a controller opens or closes valves when the $\mathrm{pH}$ goes above or below a set value. Gases are then delivered until the $\mathrm{pH}$ reaches the set value again. Different combination of gases have been used: (1) air and pure $\mathrm{CO}_{2}$, (2) $\mathrm{CO}_{2}$-free air and pure $\mathrm{CO}_{2}$, and (3) air, $\mathrm{CO}_{2}$-free air and pure $\mathrm{CO}_{2} . \mathrm{CO}_{2}$-free air can be produced easily using $\mathrm{CO}_{2}$ scrubbers such as soda lime or $\mathrm{NaOH}$ and $\mathrm{Ca}(\mathrm{OH})_{2}$ (C. J. Hintz, personal communication, 2008). The $\mathrm{pH}$ threshold is calculated using the desired $\mathrm{pCO}_{2}$ and total alkalinity which must either be constant or frequently measured. This method allows one to compensate for any change in the carbonate chemistry due to photosynthesis and respiration or, in the case of open culture systems, to changes in the source water. However, it does not compensate for changes in total alkalinity that would result from precipitation and dissolution of $\mathrm{CaCO}_{3}$ which could occur between measurements of total alkalinity. Hence, the carbonate chemistry can be maintained with good efficiency in the culture vessel, e.g. with variability of $\mathrm{pCO}_{2}$ better than $\pm 10 \mu \mathrm{atm}$. The main drawback of this technique is that the $\mathrm{pH}$ electrode must be frequently calibrated in order to account for drift. Hence, the second technique of bubbling with premixed gases may be attractive. Air with the desired $\mathrm{pCO}_{2}$ can be produced using gas mixing pumps or purchased.

Another approach would be to control atmospheric $\mathrm{pCO}_{2}$ to the desired level in the laboratory or growth cabinet in which the experiments are carried out. A simple air pump can then be used to bubble the experimental seawater. To the best of our knowledge, this technique has yet to be used in the context of ocean acidification.

Seawater aeration by bubbling may lead to difficulties in phytoplankton cultures (Shi et al., 2009). It may also enhance the coagulation of organic matter (Engel et al., 2004). This coagulation may be critical for studies investigating the response of microbial communities because their metabolism depends on the respective abundance of dissolved and particulate organic matter. This drawback may be avoided by enclosing the community in a dialysis bag, which is itself enclosed in a container bubbled with a gas having the desired $\mathrm{pCO}_{2}$ (M. Weinbauer, personal communication, 2008). Such bags are permeable to gases and small molecules in solution but impermeable to larger molecules and particles.

\subsection{Addition of high- $\mathrm{CO}_{2}$ sea water}

Dissolved inorganic carbon (DIC) and total alkalinity (TA) are conservative quantities with respect to mixing (WolfGladrow et al., 2007). Hence, when two water parcels are mixed, the amount of a solute in the mixture equals the sum of the amounts of this solute in the two initial water parcels. Hence:

$[\mathrm{DIC}]_{\text {mixed }} \times M_{\text {mixed }}=[\mathrm{DIC}]_{s w} \times M_{s w}+[\mathrm{DIC}]_{\text {high } \mathrm{CO}_{2}} \times M_{\text {high CO}}$ $[\mathrm{TA}]_{\text {mixed }} \times M_{\text {mixed }}=[\mathrm{TA}]_{s w} \times M_{s w}+[\mathrm{TA}]_{\text {high } \mathrm{CO}_{2}} \times M_{\text {high } \mathrm{CO}_{2}}$

Where the subscripts "sw" and "high $\mathrm{CO}_{2}$ ", respectively indicate concentrations in the normal and high $\mathrm{CO}_{2}$ seawater. Concentrations are in $\mu \mathrm{mol} \mathrm{kg}-1$ and $M$ is the mass in $\mathrm{kg}$. The seacarb function pmix estimates the carbonate chemistry after mixing of two water samples.

Example: one mixes, in a closed system, $0.99623 \mathrm{~kg}$ of seawater having a TA of $2325 \mu \mathrm{mol} \mathrm{kg}{ }^{-1}$, and $\mathrm{pCO}_{2}$ of $384 \mu \mathrm{atm}$ with $0.00377 \mathrm{~kg}$ of seawater having a TA of $2325 \mu \mathrm{mol} \mathrm{kg} \mathrm{kg}^{-1}$ and saturated with $\mathrm{CO}_{2}$ $\left(\mathrm{pCO}_{2}=1 \times 10^{6} \mu \mathrm{atm}\right)$. The weight fraction, wf, is $3.76 \times 10^{-3}$. Salinity is 34.9 , temperature is $18.9^{\circ} \mathrm{C}$ 
Table 2. Seawater carbonate chemistry in 2007, 2100, and after perturbation. The total alkalinity (TA), partial pressure of $\mathrm{CO}_{2}$ in seawater $\left(\mathrm{pCO}_{2 s w}\right)$, salinity and temperature were used to derive all other parameters using the seacarb package (Lavigne et al., 2008) except for manipulations of the calcium concentration for which DIC was used rather than $\mathrm{pCO}_{2} s w$. For simplicity, it is assumed that temperature, salinity and total alkalinity in 2100 are identical to their 2007 values, respectively $18.9^{\circ} \mathrm{C}, 34.9$ and $2325 \times 10^{-6} \mathrm{~mol} \mathrm{~kg}^{-1}$, and the concentrations of total phosphate and silicate were set to 0 . The seawater $\mathrm{pCO}_{2}$ was set to $384 \mu \mathrm{atm}$ in 2007 (Keeling et al., 2008) and $793 \mu$ atm in 2100 (according to the A2 SRES emission scenario; Plattner et al., 2001). The main body of the text provides further information. (a): $\times 10^{-9} \mathrm{~mol} \mathrm{~kg}^{-1},(\mathrm{~b}): \times 10^{-6} \mathrm{~mol} \mathrm{~kg}^{-1}$.

\begin{tabular}{|c|c|c|c|c|c|c|c|c|c|c|}
\hline & $\begin{array}{c}\mathrm{pCO}_{2 s w} \\
(\mu \mathrm{atm})\end{array}$ & $\begin{array}{c}\mathrm{pH}_{T} \\
(-)\end{array}$ & $\begin{array}{c}{\left[\mathrm{H}^{+}\right]} \\
\text {(a) }\end{array}$ & $\begin{array}{l}\mathrm{TA} \\
\text { (b) }\end{array}$ & $\begin{array}{l}\text { DIC } \\
\text { (b) }\end{array}$ & $\begin{array}{c}{\left[\mathrm{CO}_{2}\right]} \\
\text { (b) }\end{array}$ & $\begin{array}{c}{\left[\mathrm{HCO}_{3}^{-}\right]} \\
\text {(b) }\end{array}$ & $\begin{array}{c}{\left[\mathrm{CO}_{3}^{2-}\right]} \\
\text { (b) }\end{array}$ & $\begin{array}{l}\Omega_{c} \\
(-)\end{array}$ & $\begin{array}{l}\Omega_{a} \\
(-)\end{array}$ \\
\hline Year 2007 & 384 & 8.065 & 8.6 & 2325 & 2065 & 12.8 & 1865 & 187 & 4.5 & 2.9 \\
\hline Year 2100 & 793 & 7.793 & 16.1 & 2325 & 2191 & 26.4 & 2055 & 110 & 2.6 & 1.7 \\
\hline Gas bubbling & 793 & 7.793 & 16.1 & 2325 & 2191 & 26.4 & 2055 & 110 & 2.6 & 1.7 \\
\hline Addition of high- $\mathrm{CO}_{2}$ seawater & 792 & 7.793 & 16.1 & 2325 & 2191 & 26.4 & 2055 & 110 & 2.6 & 1.7 \\
\hline Addition of $\mathrm{CO}_{3}^{2-}$ and $\mathrm{HCO}_{3}^{-}$; closed sys. & 793 & 7.942 & 11.4 & 3406 & 3146 & 26.4 & 2901 & 218 & 5.2 & 3.4 \\
\hline Addition of $\mathrm{CO}_{3}^{2-}$ and $\mathrm{HCO}_{3}^{-}$; open sys. & 384 & 8.207 & 6.2 & 3406 & 2950 & 12.8 & 2580 & 357 & 8.5 & 5.5 \\
\hline Acid addition; closed sys. & 793 & 7.768 & 17.1 & 2184 & 2065 & 26.4 & 1940 & 98 & 2.3 & 1.5 \\
\hline Acid addition; open sys. & 384 & 8.042 & 9.1 & 2184 & 194 & 12.8 & 1767 & 167 & 4 & 2.6 \\
\hline \multicolumn{11}{|l|}{ Addition of: } \\
\hline $\mathrm{CO}_{3}^{2-}$ and $\mathrm{HCO}_{3}^{-} ;$closed sys. & 400 & 8.073 & 8.4 & 2467 & 2191 & 13.3 & 1977 & 201 & 4.8 & 3.1 \\
\hline followed by acid addition; closed sys. & 793 & 7.793 & 16.1 & 2325 & 2191 & 26.4 & 2055 & 110 & 2.6 & 1.7 \\
\hline Manipulation of $\left[\mathrm{Ca}^{2+}\right]$ & 384 & 8.065 & 8.6 & 2325 & 2065 & 12.8 & 1866 & 187 & 2.6 & 1.7 \\
\hline
\end{tabular}

and calculations are made for surface waters. The command needed is:

pmix $($ flag $=24, \operatorname{var} 1=384, \operatorname{var} 2=2325 \mathrm{e}-6, \mathrm{pCO} 2 \mathrm{~s}=1 \mathrm{e} 6$, $\mathrm{wf}=3.76 \mathrm{e}-3, \mathrm{~S}=34.9, \mathrm{~T}=18.9$ )

This produces seawater with a final $\mathrm{pCO}_{2}$ of $792 \mu$ atm (the $1 \mu \mathrm{atm}$ difference with the target value is due to rounding errors) and all parameters of the carbonate chemistry in 2100 are perfectly reproduced. To the best of our knowledge, this approach has only been used twice: in mesocosms by Schulz et al. (unpublished data) and in the laboratory by C. McGraw (personal communication, 2009). It is therefore not possible to evaluate its pros and cons at this stage.

\subsection{Addition of $\mathrm{CO}_{3}^{2-}$ and/or $\mathrm{HCO}_{3}^{-}$}

Dissolved inorganic carbon and total alkalinity can be increased by adding $\mathrm{CO}_{3}^{2-}$ in the form of $\mathrm{Na}_{2} \mathrm{CO}_{3}$ and/or by adding $\mathrm{HCO}_{3}^{-}$in the form of $\mathrm{NaHCO}_{3}$. In closed systems, the change in DIC generated by these additions is proportional to the changes in concentration: $1 \times \Delta \mathrm{CO}_{3}^{2-}$ and $1 \times \Delta \mathrm{HCO}_{3}^{-}$. The contribution of these anions to TA is proportional to the product of their charge and concentration. Thus: TA increases by $2 \times \Delta \mathrm{CO}_{3}^{2-}$ and $1 \times \Delta \mathrm{HCO}_{3}^{-}$. The changes in the carbonate chemistry generated by manipulations of total alkalinity therefore depend on the proportion of $\mathrm{CO}_{3}^{2-}$ and $\mathrm{HCO}_{3}^{-}$added (Fig. 3). This approach can be used to keep the $\mathrm{pH}$ constant or combined with addition of acid to keep TA constant (see Sect. 3.5).

In an open system, the carbonate system re-equilibrates through air-sea $\mathrm{CO}_{2}$ gas exchange after adding chemicals. At equilibrium:

$$
\begin{aligned}
\mathrm{CO}_{3}^{2-}+\mathrm{H}^{+} & \rightarrow \mathrm{HCO}_{3}^{-} \\
\mathrm{HCO}_{3}^{-}+\mathrm{H}^{+} & \rightarrow \mathrm{CO}_{2}+\mathrm{H}_{2} \mathrm{O}
\end{aligned}
$$

The seacarb function pTA computes the changes in the carbonate chemistry due to addition of $\mathrm{CO}_{3}^{2-}$ and/or $\mathrm{HCO}_{3}^{-}$.

Example: $\mathrm{HCO}_{3}^{-}\left(1081 \times 10^{-6} \mathrm{~mol} \mathrm{~kg}^{-1}\right)$ is added to seawater for which $\mathrm{pCO}_{2}(384 \mu \mathrm{atm})$ and TA $\left(2325 \mu \mathrm{mol} \mathrm{kg}{ }^{-1}\right)$ are known. No $\mathrm{CO}_{3}^{2-}$ is added. The atmospheric $\mathrm{pCO}_{2}$ is $384 \mu \mathrm{atm}$, salinity is 34.9 , temperature is $18.9^{\circ} \mathrm{C}$ and calculations are made for surface waters. The respective commands in a closed and open system are:

pTA $($ flag $=24$, sys $=0, \operatorname{var} 1=384$, var2 $=2325 \mathrm{e}-6, \mathrm{pCO} 2 \mathrm{a}=384$, co3 $=0 \mathrm{e}-6$, hco3=1081e- $6, \mathrm{~S}=34.9, \mathrm{~T}=18.9$ )

pTA $($ flag $=24$, sys $=1$, var $1=384$, var2 $=2325 \mathrm{e}-6, \operatorname{pCO} 2 \mathrm{a}=384$, co3=0e-6, hco3=1081e- $6, \mathrm{~S}=34.9, \mathrm{~T}=18.9$ )

Results are shown in Fig. 3 and Table 2. In a closed system, the target $\mathrm{pCO}_{2}$ of $793 \mu \mathrm{atm}$ is reached but all other parameters of the carbonate system are very different from their values expected in $2100 . \mathrm{pH}$ is higher than it should be (7.942 instead of 7.793) and TA, DIC, $\left[\mathrm{CO}_{3}^{2-}\right]$, and the 

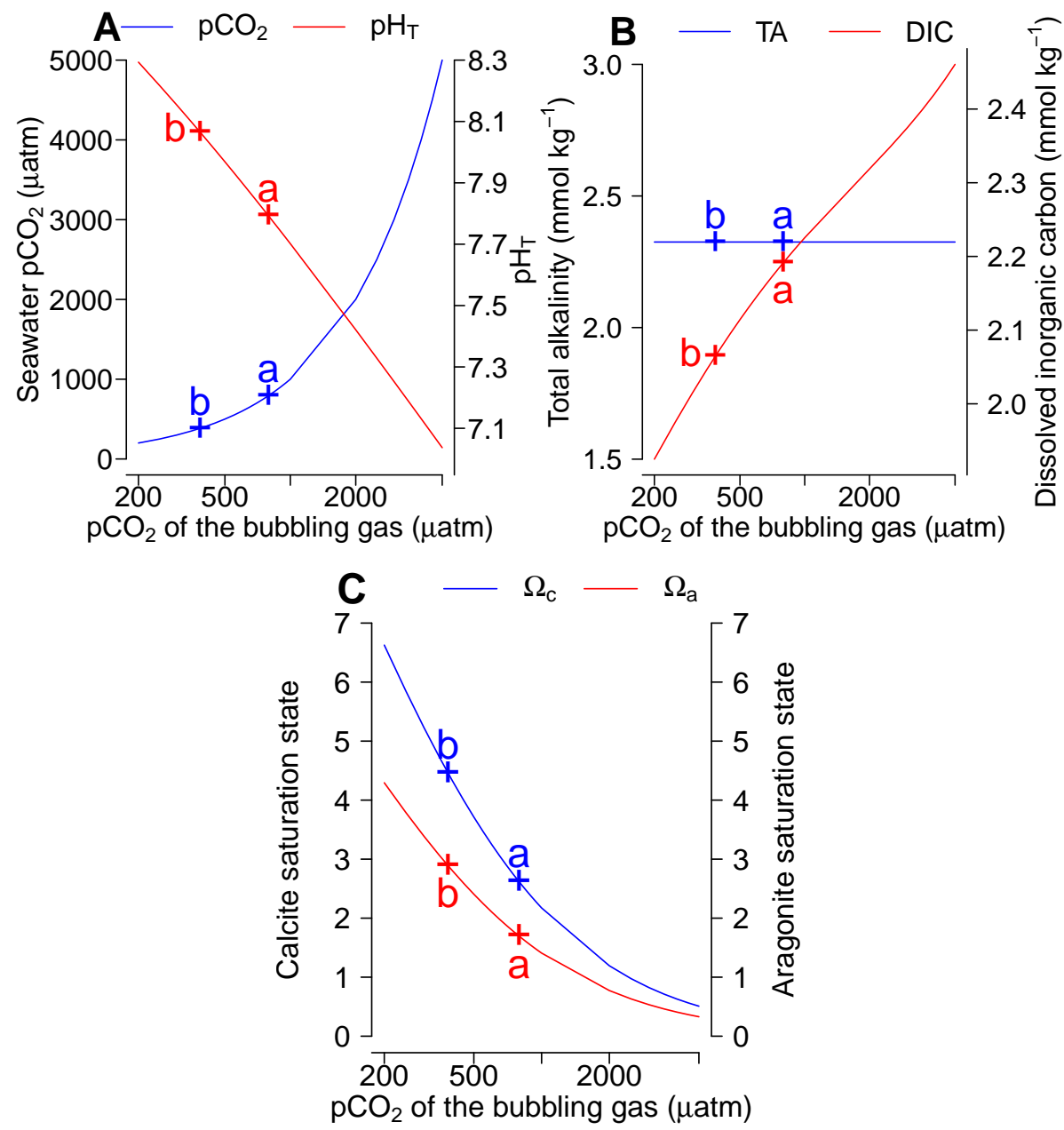

Fig. 1. Effect of bubbling seawater with gases of varying $\mathrm{pCO}_{2}$ on the carbonate chemistry of seawater as computed with the seacarb function pgas. The letters "b" and "a" indicate, respectively, the value of a parameter before and after perturbation for the example described in the text.

saturation states of aragonite and calcite $\left(\Omega_{a}\right.$ and $\left.\Omega_{c}\right)$ are higher than the target values. They are even higher than the values of the initial seawater. Those differences are magnified in open systems.

Manipulation of total alkalinity has often been used to investigate the physiological response to changes in the carbonate chemistry (e.g. Swift and Taylor, 1966). Marubini and Thake (1999) used bicarbonate additions to test the hypothesis that the supply of DIC limits coral calcification. Langdon et al. (2000) used this approach in the Biosphere 2 coral reef mesocosm. They added $\mathrm{NaHCO}_{3}$ and $\mathrm{Na}_{2} \mathrm{CO}_{3}$ to increase the $\mathrm{CaCO}_{3}$ saturation state. Since the experiment lasted several months, additions of $\mathrm{CaCl}_{2}$ were used to restore a normal $\mathrm{Ca}^{2+}$ concentration. The manipulations of the $\mathrm{Ca}^{2+}$ concentration is described in Sect. 3.6.

\subsection{Addition of strong acids and bases}

The carbonate chemistry can be manipulated by addition of a strong acid or a strong base, such as $\mathrm{HCl}$ and $\mathrm{NaOH}$, which completely dissociate in seawater. Adding of a strong acid or base to a system closed to the atmosphere does not alter the concentration of dissolved inorganic carbon but modifies total alkalinity. TA decreases when adding an acid and increases after addition of a base.

The change of total alkalinity after addition of a strong acid or base in a system open to the atmosphere is identical to that described above for a closed system. However, the concentration of DIC is modified through $\mathrm{CO}_{2}$ exchange at the air-water interface because the partial pressures of $\mathrm{CO}_{2}$ in the atmosphere and seawater equilibrate.

The seacarb function $\mathrm{ppH}$ calculates the changes in the carbonate chemistry during $\mathrm{pH}$ manipulations. The change in salinity due to the addition of acid or base is negligible. 

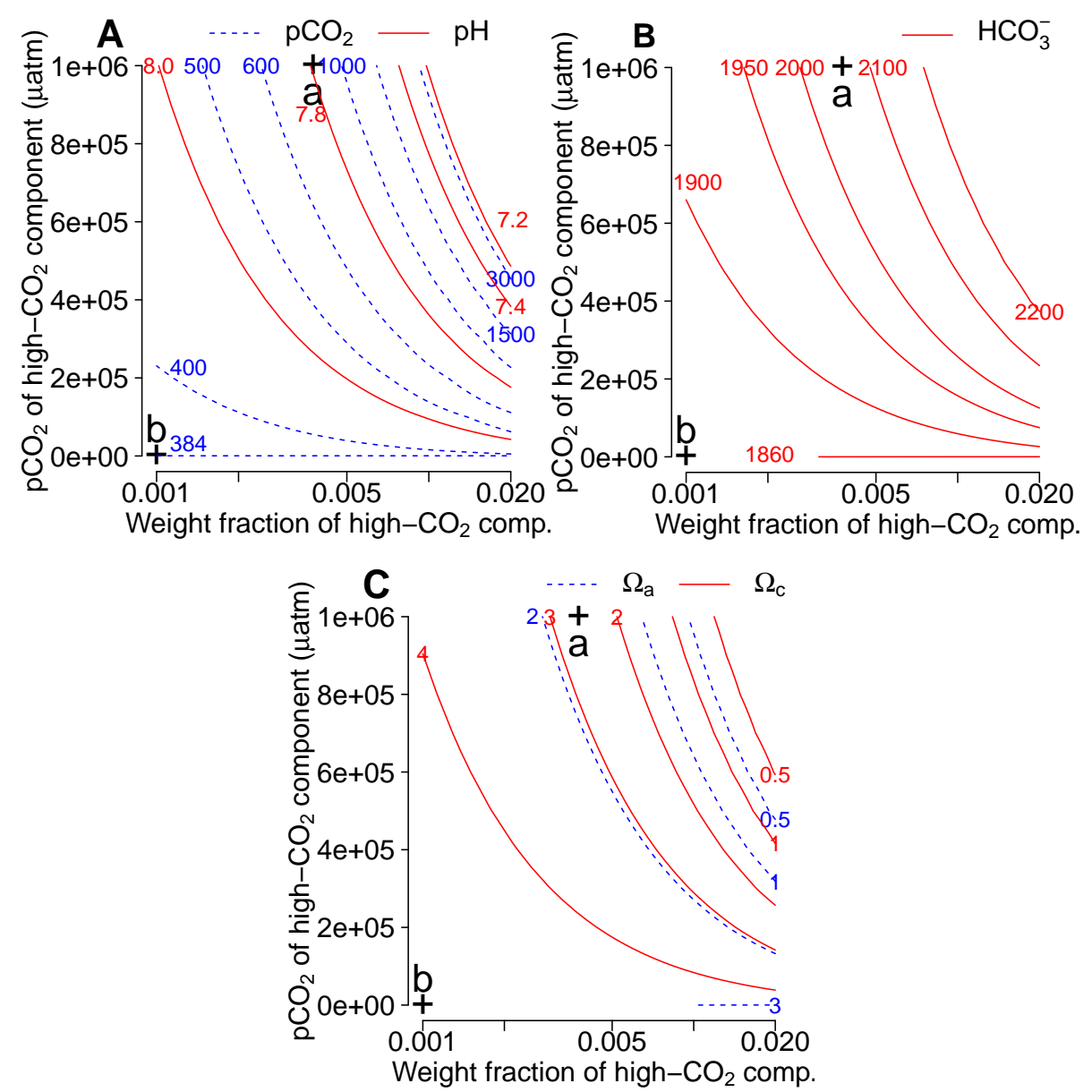

Fig. 2. Effect of mixing with various weight fractions of high- $\mathrm{pCO}_{2}$ seawater on the carbonate chemistry of seawater in a closed system as computed with the seacarb function pmix. The letters "b" and "a" indicate, respectively, the value of a parameter before and after perturbation for the example described in the text.

Example: a volume of $14.08 \mathrm{ml}$ of $0.01 \mathrm{~N} \mathrm{HCl}$ is added to $1 \mathrm{~kg}$ of seawater having a known $\mathrm{pCO}_{2}(384 \mu \mathrm{atm})$ and TA $\left(2325 \mu \mathrm{mol} \mathrm{kg}{ }^{-1}\right)$. The atmospheric $\mathrm{pCO}_{2}$ is $384 \mu \mathrm{atm}$, salinity is 34.9 and temperature is $18.9^{\circ} \mathrm{C}$. Calculations are made for surface waters. The commands needed in a closed and open system are:

$\operatorname{ppH}($ flag $=24$, sys $=0, \operatorname{var} 1=384, \operatorname{var} 2=2325 \mathrm{e}-6, \mathrm{pCO} 2 \mathrm{a}=384$, vol $=-14.08 \mathrm{e}-3, \mathrm{~N}=0.01, \mathrm{~S}=34.9, \mathrm{~T}=18.9$ )

$\operatorname{ppH}($ flag $=24$, sys $=1$, var $1=384$, var2 $=2325 \mathrm{e}-6, \operatorname{pCO} 2 \mathrm{a}=384$, vol $=-14.08 \mathrm{e}-3, \mathrm{~N}=0.01, \mathrm{~S}=34.9, \mathrm{~T}=18.9$ )

Results are shown in Fig. 4 and Table 2. The target $\mathrm{pCO}_{2}$ of $793 \mu \mathrm{atm}$ is reached in a closed system but the $\mathrm{pH}$ is lower than the value expected in 2100 (7.768 instead of 7.793, corresponding to an increase of $2.9 \%$ in $\left[\mathrm{H}^{+}\right]$that resulting from the decrease in total alkalinity generated by the addition of acid). This is an undesirable effect of the direct manipulation of $\mathrm{pH}$ as TA will not change significantly during the course of this century (Table 1). As a result, DIC, $\mathrm{HCO}_{3}^{-}, \mathrm{CO}_{3}^{2-}$, $\Omega_{a}$ and $\Omega_{c}$ are lower than their target values. However, it is possible to restore TA to its initial level by adding $\mathrm{CO}_{3}^{2-}$ and/or $\mathrm{HCO}_{3}^{-}$, an approach that is described in Sect. 3.5. Obviously, due to gas exchange at the air-water interface, $\mathrm{pCO}_{2}$ and other parameters of the carbonate chemistry cannot be successfully adjusted by a one-time addition of acid in an open system.

Addition of acid has often been used in studies of the impact of ocean acidification on organisms. The first purposeful experiment is that of Agegian (1985) who looked at the response of coralline algae.

\subsection{Addition of strong acid as well as $\mathrm{CO}_{3}^{2-}$ and/or $\mathrm{HCO}_{3}^{-}$}

As mentioned in Sect. 3.4, the addition of acid does not allow to fully mimic the changes in carbonate chemistry expected during the present century but the addition of $\mathrm{CO}_{3}^{2-}$ and/or $\mathrm{HCO}_{3}^{-}$followed by addition of acid circumvents this 


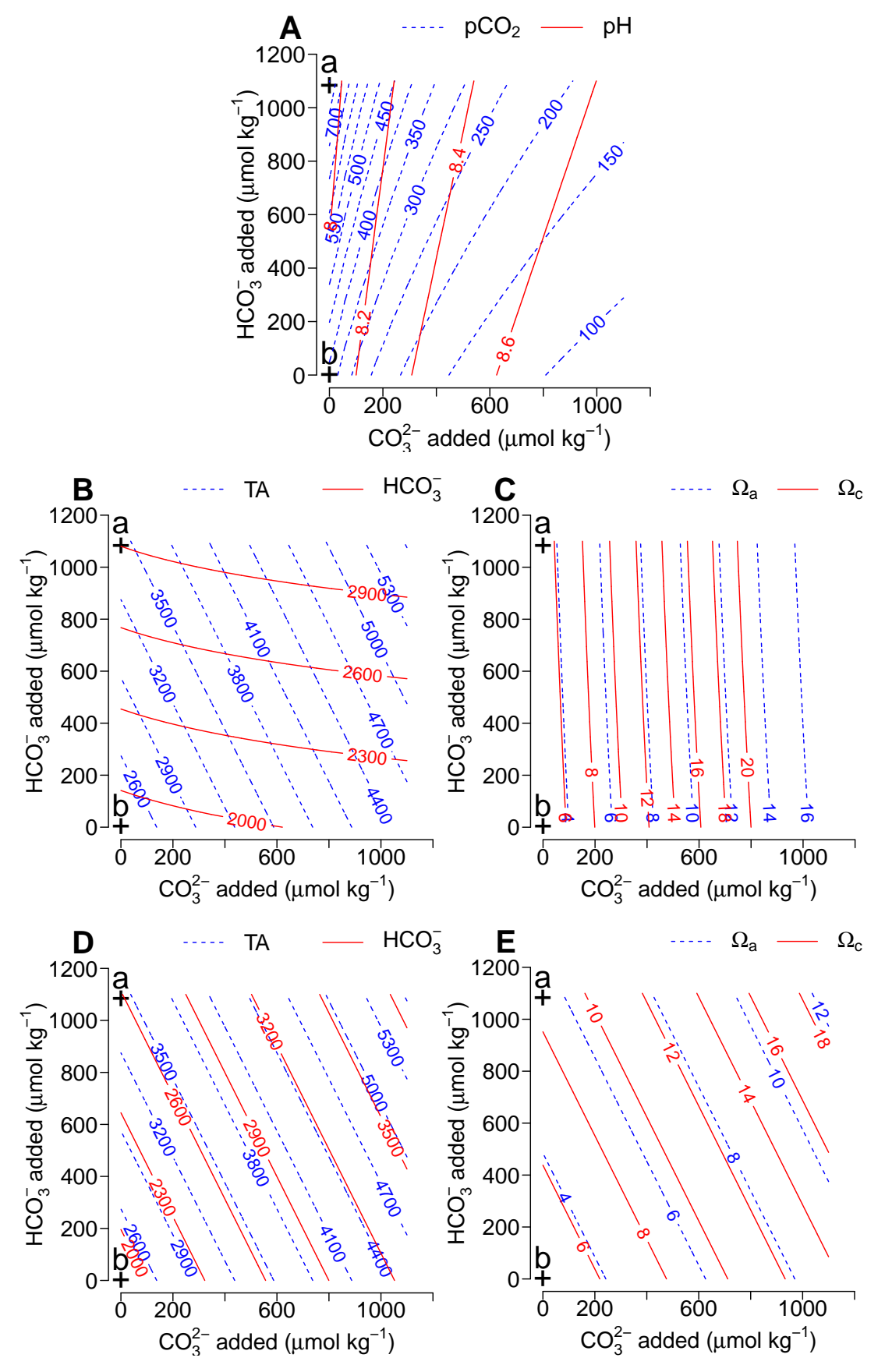

Fig. 3. Effect of adding $\mathrm{CO}_{3}^{2-}$ and/or $\mathrm{HCO}_{3}^{-}$on the carbonate chemistry of seawater in closed (A, B and $\left.\mathbf{C}\right)$ and open systems (D and $\left.\mathbf{E}\right)$ as computed with the seacarb function pTA. The letters "b" and "a" indicate, respectively, the value of a parameter before and after perturbation for the example described in the text.

problem. The first addition elevates DIC to the desired level while adding acid (at constant DIC) precisely cancels out the increase in TA resulting from the addition of $\mathrm{CO}_{3}^{2-}$ and/or $\mathrm{HCO}_{3}^{-}$.

There is no specific seacarb function to handle this approach. The changes in the carbonate chemistry can be calculated using successively the functions pTA and $\mathrm{ppH}$.
Example: $\mathrm{HCO}_{3}^{-}\left(111.2 \times 10^{-6} \mathrm{~mol} \mathrm{~kg}^{-1}\right)$ and $\mathrm{CO}_{3}^{2-}$ $\left(15.3 \times 10^{-6} \mathrm{~mol} \mathrm{~kg}^{-1}\right)$ are added to seawater for which $\mathrm{pCO}_{2}(384 \mu \mathrm{atm})$ and TA $\left(2325 \mu \mathrm{mol} \mathrm{kg}{ }^{-1}\right)$ are known. The atmospheric $\mathrm{pCO}_{2}$ is $384 \mu \mathrm{atm}$, salinity is 34.9 , temperature is $18.9^{\circ} \mathrm{C}$ and calculations are made for surface waters. Then, $14.18 \mathrm{ml}$ of $0.01 \mathrm{~N} \mathrm{HCl}$ is added. The commands needed are: 

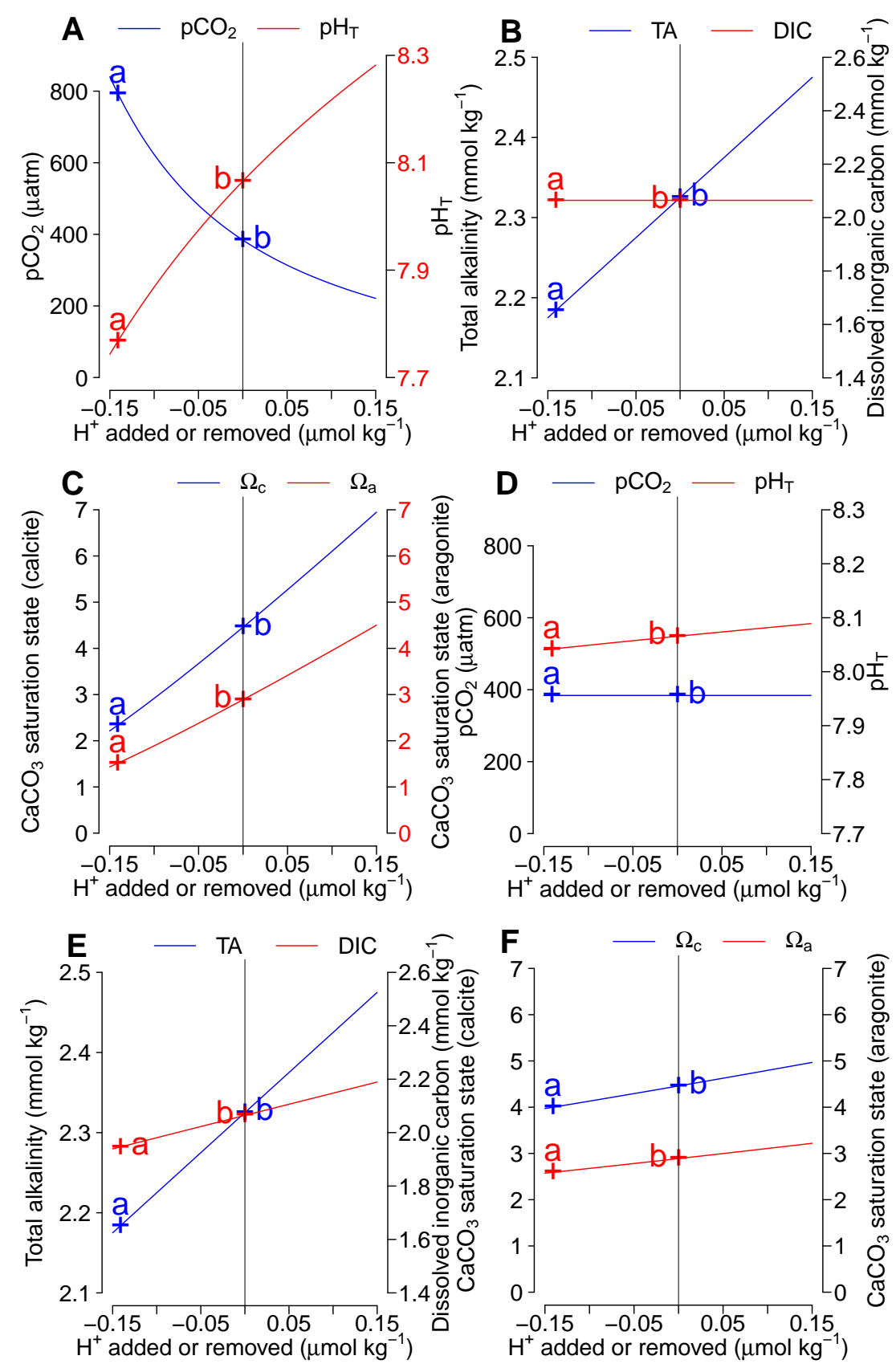

Fig. 4. Effect of adding a strong acid or a strong base on the carbonate chemistry of seawater in closed (A, B and C) and open systems (D, $\mathbf{E}$ and $\mathbf{F}$ ) as computed with the seacarb function pgas. By convention, addition of acid is negative whereas addition of base is positive. The letters " $b$ " and "a" indicate, respectively, the value of a parameter before and after perturbation for the example described in the text.

tmp $=$ pTA (flag $=24$, sys $=0, \operatorname{var} 1=384$, var $2=2325 \mathrm{e}-6$,

$\mathrm{pCO} 2 \mathrm{a}=384, \mathrm{co3}=15.3 \mathrm{e}-6, \mathrm{hco} 3=111.2 \mathrm{e}-6, \mathrm{~S}=34.9, \mathrm{~T}=18.9$ )

$\mathrm{ppH}(\mathrm{flag}=24, \mathrm{sys}=0, \operatorname{var} 1=\mathrm{tmp} \$ \mathrm{pCO} 2[2]$,

var2=tmp $\$$ ALK[2], $\mathrm{pCO} 2 \mathrm{a}=384$, vol $=-14.18 \mathrm{e}-3, \mathrm{~N}=0.01$, $\mathrm{S}=34.9, \mathrm{~T}=18.9$ )
Results are shown in Table 2. The first addition raises DIC to the desired level of $2191 \times 10^{-6} \mathrm{~mol} \mathrm{~kg}^{-1}$ but increases TA to a value higher than the target (2467 vs. $\left.2325 \times 10^{-6} \mathrm{~mol} \mathrm{~kg}^{-1}\right)$. The subsequent addition of $\mathrm{HCl}$ restores TA to the desired value without affecting DIC. After both additions, all carbonate parameters are at the target values (Table 2). 
To our knowledge, the first paper which used addition of acid, base and $\mathrm{NaHCO}_{3}$ to manipulate the carbonate chemistry within a range comparable to ocean acidification is that of Borowitzka (1981) who investigated, in the laboratory, the response of photosynthesis and calcification of an articulated coralline red algae.

\subsection{Manipulation of the $\mathrm{Ca}^{2+}$ concentration}

Although manipulating the calcium concentration does not technically alter the carbonate chemistry per se, this approach has been used in the context of ocean acidification. The reason is that some calcifying organisms, such as corals, respond to the calcium carbonate saturation state of seawater $(\Omega)$ which is expressed as:

$\Omega=\frac{\left[\mathrm{Ca}^{2+}\right]_{s w} \times\left[\mathrm{CO}_{3}^{2-}\right]_{s w}}{K_{s p}^{*}}$

where $\left[\mathrm{Ca}^{2+}\right]_{s w}$ and $\left[\mathrm{CO}_{3}^{2-}\right]_{s w}$ are the concentrations of calcium and carbonate in seawater, respectively, and $K_{s p}^{*}$ is the solubility product at the in situ conditions of temperature, salinity and pressure (Zeebe and Wolf-Gladrow, 2001). It can readily be appreciated that the changes in $\Omega$ resulting from the decrease in $\left[\mathrm{CO}_{3}^{2-}\right]_{s w}$ driven by ocean acidification can be mimicked by altering $\left[\mathrm{CO}_{3}^{2-}\right]_{s w}$. This approach involves the use of artificial seawater (Gattuso et al., 1998). It is recommended to use the simplied synthetic seawater recipe based on DOE (1994) as described by Gattuso et al. (1998) and because it is the basis of the synthetic seawater that has been used to determine a variety of equilibrium constants for use in seawater.

The seacarb function pCa estimates the changes in $\Omega_{c}$ and $\Omega_{a}$ resulting from the manipulation of the $\left[\mathrm{Ca}^{2+}\right]_{s w}$ concentration. Note that this function does not account for the effect of the changes on the calcium concentration of the dissociation constants of carbonic acid and on the solubility product of $\mathrm{CaCO}_{3}$ (Ben-Yaakov and Goldhaber, 1973).

Example: artificial seawater is made with a known TA $\left(2325 \mu \mathrm{mol} \mathrm{kg}{ }^{-1}\right)$ and DIC $(2064 \mu \mathrm{mol} \mathrm{kg}-1)$. The calcium concentration is set to $6.03 \times 10^{-6} \mathrm{~mol} \mathrm{~kg}^{-1}$. The command needed is:

$\mathrm{pCa}($ flag $=15$, var $1=2325 \mathrm{e}-6$, var $2=2064 \mathrm{e}-6$, $\mathrm{Ca}=6.03 \mathrm{e}-3, \mathrm{~S}=34.9, \mathrm{~T}=18.9$ )

Results are shown in Fig. 5 and Table 2. The saturation states of aragonite and calcite expected in 2100 are well reproduced without affecting any of the other parameters of the carbonate system which remain at their 2008 values.

This approach has been used to investigate the response of corals (Gattuso et al., 1998) and coccolithophores (Trimborn et al., 2007) to changes in the saturation state of calcium carbonate. It has also been used to replenish calcium when its concentration decreases below its natural levels during longterm experiments with calcifiers (e.g. Langdon et al., 2000).

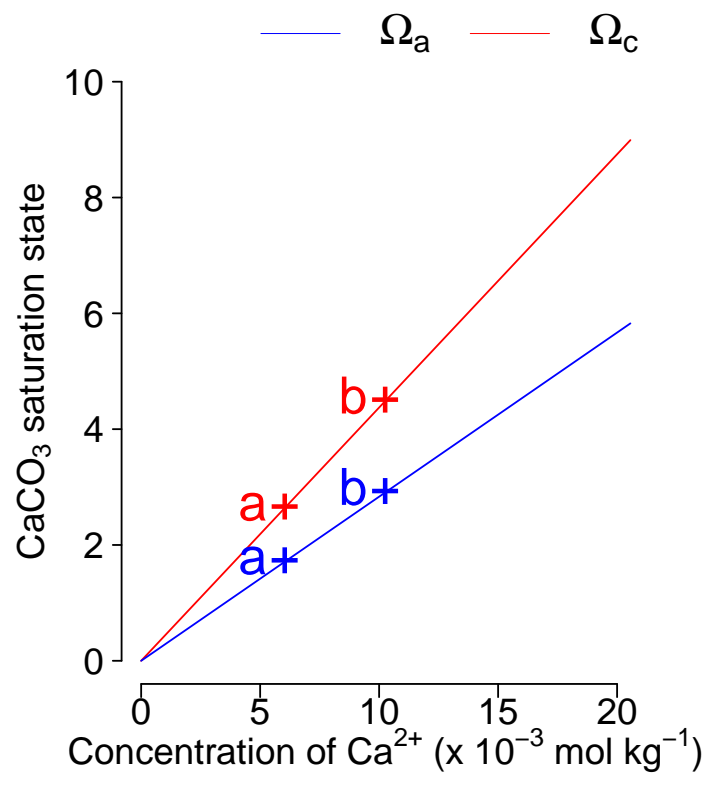

Fig. 5. Calcium carbonate saturation state as a function of the calcium concentration as computed with the seacarb function pCa. The letters "b" and "a" indicate, respectively, the value of the calcium carbonate saturation state before and after perturbation for the example described in the text.

\section{Discussion and conclusion}

Three approaches closely mimic the on-going and future changes in the seawater carbonate chemistry: gas bubbling, addition of high- $\mathrm{CO}_{2}$ seawater, and combined addition of acid and bicarbonate and/or carbonate. All three methods increase dissolved inorganic carbon at constant total alkalinity, a situation that closely resembles the changes in the carbonate chemistry that have occurred during the last 200 years and are expected to continue during the next few hundreds years. All three approaches therefore offer precise control of carbonate chemistry variables, that reach target values at the beginning of a perturbation experiment. Gas bubbling is the easiest to implement and can be used to maintain constant conditions over long periods of time. However, during bubbling, biological processes (e.g., calcification, dissolution of $\mathrm{CaCO}_{3}$, nutrient uptake and release) can alter the carbonate chemistry by changing total alkalinity even though the concentration of $\mathrm{pCO}_{2}$ remains constant. Also, in all three approaches, calcification can deplete the concentration of $\mathrm{Ca}^{2+}$ when the organism to volume ratio is high or the incubation time long.

The approach of adding $\mathrm{CO}_{3}^{2-}$ and/or $\mathrm{HCO}_{3}^{-}$appears to be of limited practical use because most carbonate variables reach values that are far from target values. Several studies have added acid to manipulate the carbonate chemistry. Although this technique offers precise control of $\mathrm{pCO}_{2}$ in systems closed to the atmosphere, it also alters total alkalinity 
which drives other carbonate system variables to levels far from those expected in the future. That is, $\mathrm{pH}$ is lower than its target value, DIC remains unchanged (whereas it increases with natural ocean acidification), and the $\mathrm{CaCO}_{3}$ saturation states as well as the concentrations of bicarbonate and carbonate are higher than the target values. To avoid this drawback, it is recommended to first add bicarbonate or carbonate, or both, to increase DIC, before adding acid.

Iglesias-Rodriguez et al. (2008a) have recently reported that, in contrast to previous reports, calcification of the coccolithophore Emiliania huxleyi increases at elevated $\mathrm{pCO}_{2}$. They argued that this is due to the different approaches used to manipulate the carbonate chemistry and that the approach of gas bubbling (changing DIC at constant TA) is superior to the approach of adding acid (changing TA at constant DIC) (Iglesias-Rodriguez et al., 2008a,b). The argument is that the addition of acid does not reproduce the increase in the $\mathrm{HCO}_{3}^{-}$concentration occurring from natural ocean acidification whereas gas bubbling does reproduce it. The authors claim that $\mathrm{HCO}_{3}^{-}$may stimulate photosynthesis and, in turn, calcification. They conclude that experiments using addition of acid demonstrating that calcification declines at lower $\mathrm{pH}$, confounded the issue. This statement is misleading, although there is no doubt that gas bubbling better mimics the future carbonate chemistry (see above as well as Table 2). In contrast to the claims by Iglesias-Rodriguez et al. (2008a,b), several previous perturbation experiments were also carried out with gas bubbling and reported lower rates of calcification of coccolithophores at lower $\mathrm{pH}$ and higher $\mathrm{pCO}_{2}$ (Sciandra et al., 2003; Delille et al., 2005; Feng et al., 2008). Additionally, the concentrations of $\mathrm{CO}_{2}, \mathrm{HCO}_{3}^{-}, \mathrm{CO}_{3}^{2-}$, and $\mathrm{H}^{+}$all change in the same direction with both approaches: gas bubbling and acid addition (compare Fig. 1a-c with Fig. 4a-c; Table 2). Hence, the magnitude of biological responses may be different, but should at least tend to go in the same direction. Differences in the two approaches cannot explain biological responses going in opposite directions. Finally, perturbation experiments carried out using gas bubbling can also lead to poor control of the carbonate chemistry, for example, when the experiments last too long or when the biomass-to -volume ratio is too large (see above). Although the cause of the discrepancy in the response of calcification by the coccolithophore E. huxleyi to ocean acidification remains a matter of debate (e.g., Riebesell et al., 2008; Shi et al., 2009), it does not appear to be related to the approach used to perform the manipulation of the carbonate chemistry in perturbation experiments.

Fortunately, the situation seems clearer in zooxanthellate scleractinian corals. Schneider and Erez (2006) measured the rate of calcification under constant DIC, constant $\mathrm{pH}$ and constant $\mathrm{pCO}_{2}$ and showed that calcification is controlled by the concentration of $\mathrm{CO}_{3}^{2-}$, the future value of which is relatively well mimicked by adding acid.

Our goal here has been to provide the appropriate computational tools and to highlight the positive and negative aspects of the different approaches that are used to investigate ocean acidification by perturbing the carbonate chemistry. We have not addressed practical issues that must be taken into account to design and conduct perturbation experiments. To mention just a few: response time, bubbling rate, impact of autoclaving, evaporation, heat flux, impact of nutrients and temperature. These issues, as well as others, will be covered in a Guide for Best Practices in Ocean Acidification Research and Data Reporting in preparation (see http://www.epoca-project.eu/index.php/ Home/Guide-to-OA-Research/).

\section{Appendix A}

\section{A1 Gas bubbling: syntax of pgas}

The function pgas calculates the carbonate chemistry after perturbation using the $\mathrm{CO}_{2}$ partial pressure of the gas used to bubble the medium and the initial total alkalinity which is not altered by gas bubbling. The syntax is:

pgas(flag, var1, var2, pCO2g, S, T, P, Pt, Sit, k1k2, Kf, pHscale)

The input parameters below are required:

- flag: a number (1 to 24) indicating which couple of parameters of the carbonate system is known. For example, flag is 8 when $\mathrm{pH}_{T}$ and total alkalinity are known.

- var1 and var2: the values of the two parameters of the carbonate system prior to the perturbation which are known $\left(\mathrm{pH}_{T}\right.$ and alkalinity in the example above). See the seacarb manual for more details, especially regarding the units.

- pCO2g is the $\mathrm{CO}_{2}$ partial pressure (in $\mu$ atm) of the gas used to bubble the medium.

- S: salinity.

- T: temperature in ${ }^{\circ} \mathrm{C}$

- P: hydrostatic pressure (P; 0 by default). Note that this function was only tested at $\mathrm{P}=0$, that is for surface waters.

- Pt: concentration of total phosphate $\left(\mathrm{mol} \mathrm{kg}^{-1} ; 0\right.$ by default).

- Sit: concentration of total silicate $\left(\mathrm{mol} \mathrm{kg}^{-1} ; 0\right.$ by default).

- k1k2: "l" for using $K_{1}$ and $K_{2}$ from Lueker et al. (2000) and "r" for using $K_{1}$ and $K_{2}$ from Roy et al. (1993), default is " $\mathrm{l} "$ 
- Kf: "pf" for using $K_{f}$ from Perez and Fraga (1987) and "dg" for using $K_{f}$ from Dickson and Riley (1979), default is "pf"

- pHscale: "T" for using the total scale, "F" for using the free scale and "SWS" for using the seawater scale, default is " $T$ "

\section{A2 Addition of high- $\mathrm{CO}_{2}$ seawater: syntax of pmix}

It is important to note that pmix assumes that the initial and high- $\mathrm{CO}_{2}$ seawater have the same total alkalinity. pmix calculates the carbonate chemistry after perturbation using the final DIC concentration calculated as described in Sect. 3.2 and the initial total alkalinity which is not altered by the mixing. The syntax is:

pmix(flag, var1, var2, pCO2s, wf, S, T, P, Pt, Sit, k1k2, Kf, pHscale)

flag, var1, var2, S, T, P, Pt, Sit, k1k2, Kf and pHscale were defined in Appendix A1. The other input parameters required are:

- pCO2s: $\mathrm{pCO}_{2}$ of the high- $\mathrm{CO}_{2}$ water in $\mu$ atm

- wf: weight fraction of the high- $\mathrm{CO}_{2}$ seawater vs. final weight

\section{A3 Addition of $\mathrm{CO}_{3}^{2-}$ and/or $\mathrm{HCO}_{3}^{-}$: syntax of pTA}

For closed systems, the function pTA calculates the carbonate chemistry after perturbation using the final DIC concentration and total alkalinity calculated as described in Sect. 3.3. For open systems, the carbonate chemistry is calculated using atmospheric $\mathrm{pCO}_{2}$, therefore assuming equilibrium of $\mathrm{pCO}_{2}$ between air and seawater, and total alkalinity calculated as described in Sect. 3.3 (as is not further altered by air-sea $\mathrm{CO}_{2}$ exchange). The syntax is:

pTA(flag, sys, var1, var2, pCO2a, co3, hco3, S, T, $\mathrm{P}, \mathrm{Pt}, \mathrm{Sit}, \mathrm{k} 1 \mathrm{k} 2, \mathrm{Kf}, \mathrm{pHscale})$

flag, var1, var2, S, T, P, Pt, Sit, k1k2, Kf and pHscale where defined above. The other input parameters below are required:

- sys: 0 if the manipulation is carried out in a system closed to the atmosphere or 1 if it is carried out in a system open to the atmosphere (in the latter case, full equilibrium between air and water is assumed).

- pCO2a: the value of atmospheric $\mathrm{pCO}_{2}$ in $\mu$ atm. It is only used in systems open to the atmosphere (i.e. sys $=1$ ).

- co3: amount of $\mathrm{CO}_{3}^{2-}$ added in $\mathrm{mol} \mathrm{kg}{ }^{-1}$.

- hco3: amount of $\mathrm{HCO}_{3}^{-}$added in $\mathrm{mol} \mathrm{kg}^{-1}$.

\section{A4 Addition of strong acids and bases: syntax of $\mathrm{ppH}$}

For closed systems, the function ppH calculates the carbonate chemistry after perturbation using the DIC concentration (which is unchanged by the addition of acid or base) and the total alkalinity which can easily be estimated as strong acids and bases completely dissociate in seawater. For open systems, the carbonate chemistry is calculated using atmospheric $\mathrm{pCO}_{2}$, therefore assuming equilibrium of $\mathrm{pCO}_{2}$ between air and seawater, and the total alkalinity after addition of acid or base as it is not further altered by air-sea $\mathrm{CO}_{2}$ exchange. The syntax is:

ppH(flag, sys, var1, var2, pCO2a, vol, N, S, T, P, Pt,

Sit, k1k2, Kf, pHscale)

flag, sys, var1, var2, $\mathrm{pCO}_{2} \mathrm{a}, \mathrm{S}, \mathrm{T}, \mathrm{P}, \mathrm{Pt}, \mathrm{Sit}, \mathrm{k} 1 \mathrm{k} 2, \mathrm{Kf}$ and pHscale were defined above.

The other input parameters required are:

- vol: the volume of acid or base added in liter. By convention, it is given a negative sign for additions of acid and a positive sign for additions of base.

- $\mathrm{N}$ : the normality of the acid or base $\left(\mathrm{mol} \mathrm{kg}^{-1}\right)$.

\section{A5 Manipulation of the $\mathrm{Ca}^{2+}$ concentration: syntax of pCa}

The function $\mathrm{pCa}$ calculates the carbonate chemistry using the standard equations of Dickson et al. (2007) except that the actual calcium concentration is used rather than the standard concentration of $0.01028 \times(S / 35) \mathrm{mol} \mathrm{kg}^{-1}$. The syntax is:

pCa(flag, sys, var1, var2, Ca, S, T, P, Pt, Sit, k1k2, $\mathrm{Kf}$, pHscale)

flag, var1, var2, S, T, P, Pt, Sit, k1k2, Kf and pHscale were defined above. $\mathrm{Ca}$ is the calcium concentration in $\mathrm{mol} \mathrm{kg}^{-1}$.

Acknowledgements. Thanks are due to G.-K. Plattner for providing model outputs, to P. Grosjean, J. C. Orr, U. Riebesell, K. Schulz and R. E. Zeebe for useful comments on an early draft of this paper, as well as to A. Dickson, A. Engel, C. Langdon, H.-O. Pörtner and the participants of the "Workshop on Best Practices for Ocean Acidification Research and Data Reporting" for helpful discussions. This work is a contribution to the "European Project on Ocean Acidification" (EPOCA) which receives funding from the European Community's Seventh Framework Programme (FP7/2007-2013) under grant agreement 211384, the BOOM project funded by the Agence Nationale de la Recherche (ANR-05-BIODIV-004) and CARBOOCEAN (FP6/511176-2).

Edited by: A. Boetius 


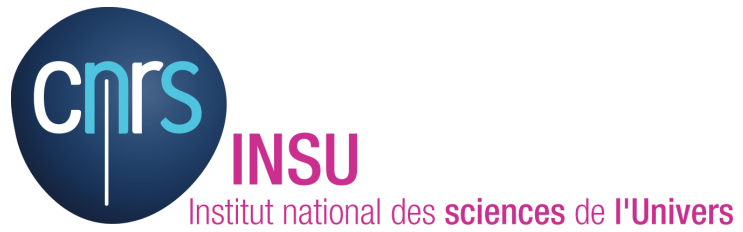

The publication of this article is financed by CNRS-INSU.

\section{References}

Agegian, C. R.: The biogeochemical ecology of Porolithon gardineri (Foslie), Ph.D. thesis, University of Hawaii, 1985.

Ben-Yaakov, S. and Goldhaber, M.: The influence of sea water composition on the apparent constants of the carbonate system, DeepSea Res., 20, 87-99, 1973.

Borowitzka, M. A.: Photosynthesis and calcification in the articulated coralline red algae Amphiroa anceps and A. foliacea, Mar. Biol., 62(1), 17-23, 1981.

Bouxin, H.: Action des acides sur le squelette des larves de l'oursin Paracentrotus lividus. Influence du pH, C. R. Soc. Biol., 94, 453455, 1926.

Delille, B., Harlay, J., Zondervan, I., Jacquet, S., Chou, L., Wollast, R., Bellerby, R. G. J., Frankignoulle, M., Borges, A. V., Riebesell, U., and Gattuso, J.-P.: Response of primary production and calcification to changes of $\mathrm{pCO}_{2}$ during experimental blooms of the coccolithophorid Emiliania huxleyi, Global Biogeochem. Cy., 19, GB2023, doi:10.1029/2004GB002318, 2005.

Dickson, A. G. and Riley, J. P.: The estimation of acid dissociation constants in seawater media from potentiometric titrations with strong base. I. The ionic product of water, Mar. Chem., 7, 89-99, 1979.

Dickson, A. G., Sabine, C. L., and Christian, J. R.: Guide to best practices for ocean $\mathrm{CO}_{2}$ measurements, PICES Special Publication, 3, 1-191, 2007.

DOE: Handbook of methods for the analysis of the various parameters of the carbon dioxide system in sea water, version 2 , ORNL/CDIAC; location is Oak Ridge, Tennessee, 1994.

Engel, A., Delille, B., Jacquet, S., Riebesell, U., Rochelle-Newall, E., Terbrggen, A., and Zondervan, I.: Transparent exopolymer particles and dissolved organic carbon production by Emiliania huxleyi exposed to different $\mathrm{CO}_{2}$ concentrations: a mesocosm experiment, Aquat. Microb. Ecol., 34(1), 93-104, 2004.

Feng, Y., Warner, M., Zhang, Y., Sun, J., Fu, F., Rose, J., and Hutchins, D.: Interactive effects of increased $\mathrm{pCO}_{2}$, temperature and irradiance on the marine coccolithophore Emiliania huxleyi (Prymnesiophyceae), Eur. J. Phycol., 43, 87-98, 2008.

Garcia, H., Locarnini, R., Boyer, T., and Antonov, J.: World Ocean Atlas 2005. Volume 4: Nutrients (phosphate, nitrate, silicate), in: NOAA Atlas NESDIS 64, edited by: Levitus, S., 1-396, US Government Printing Office, Washington, DC, 2006.

Gattuso, J.-P., Frankignoulle, M., Bourge, I., Romaine, S., and Buddemeier, R. W.: Effect of calcium carbonate saturation of seawater on coral calcification, Global Planet Change, 18, 37-46, 1998.

Iglesias-Rodriguez, M., Halloran, P., Rickaby, R., Hall, I., Colmenero-Hidalgo, E., Gittins, J., Green, D., Tyrrell, T., Gibbs, S., von Dassow, P., Rehm, E., Armbrust, E., and Boessenkool, $\mathrm{K}$.: Phytoplankton calcification in a high- $\mathrm{CO}_{2}$ world, Science, 320, 336-340, 2008a.
Iglesias-Rodriguez, M. D., Buitenhuis, E. T., Raven, J. A., Schofield, O., Poulton, A. J., Gibbs, S., Halloran, Paul, R., and de Baar, H. J. W.: Response to Comment on Phytoplankton calcification in a high- $\mathrm{CO}_{2}$ world, Science, 322, 1466c-1466c, 2008b.

Keeling, R., Piper, S., Bollenbacher, A., and Walker, J.: Atmospheric $\mathrm{CO}_{2}$ records from sites in the SIO air sampling network, in: Trends: a compendium of data on global change, Oak Ridge National Laboratory, US Department of Energy, 2008.

Kleypas, J. A., Feely, R. A., Fabry, V. J., Langdon, C., Sabine, C. L., and Robbins, L. L.: Impacts of ocean acidification on coral reefs and other marine calcifiers: a guide for future research, Institute for the Study of Society and Environment (ISSE) of the University Corporation for Atmospheric Research (UCAR), Boulder, Colorado, 2006.

Langdon, C.: Review of experimental evidence for effects of $\mathrm{CO}_{2}$ on calcification of reef builders, in: Proceedings of the 9th International Coral Reef Symposium, 1091-1098, Bali, 2000.

Langdon, C., Takahashi, T., Marubini, F., Atkinson, M., Sweeney, C., Aceves, H., Barnett, H., Chipman, D., and Goddard, J.: Effect of calcium carbonate saturation state on the rate of calcification of an experimental coral reef, Global Biogeochem. Cy., 14, 639654, 2000.

Lavigne, H., Proye, A., and Gattuso, J.-P.: seacarb 2.0, an R package to calculate parameters of the seawater carbonate system, online available at: http://cran.r-project.org/web/packages/seacarb/ index.html, 2008

Lueker, T. J., Dickson, A., and Keeling, C. D.: Ocean $\mathrm{pCO}_{2}$ calculated from dissolved inorganic carbon, alkalinity, and equations for $\mathrm{K} 1$ and $\mathrm{K} 2$ : validation based on laboratory measurements of $\mathrm{CO}_{2}$ in gas and seawater at equilibrium, Mar. Chem., 70(1-3), 105-119, 2000.

MARGO Project Members: Constraints on the magnitude and patterns of ocean cooling at the Last Glacial Maximum, Nat. Geosci., 2, 127-132, 2009.

Marubini, F. and Thake, B.: Bicarbonate addition promotes coral growth, Limnol. Oceanogr., 44(3), 716-720, 1999.

Nakićenović, N. and Swart, R. (eds.): Special report on emissions scenarios : a special report of Working Group III of the Intergovernmental Panel on Climate Change, Cambridge University Press, Cambridge, 2000.

Paul, A. and Schäfer-Neth, C.: Modeling the water masses of the Atlantic Ocean at the Last Glacial Maximum, Paleoceanography, 18, 1058, doi:10.1029/2002PA000783, 2003.

Perez, F. F., and Fraga, F.:Association constant of fluoride and hydrogen ions in seawater, Mar. Chem., 21, 161-168, 1987.

Petit, J. R., Jouzel, J., Raynaud, D., Barkov, N., Barnola, J.-M., Basile, I., Bender, M., Chappellaz, J., Davis, J., Delaygue, G., Delmotte, M., Kotlyakov, V., Legrand, M., Lipenkov, V., Lorius, C., Pépin, L., Ritz, C., Saltzman, E., and Stievenard, M.: Vostok ice core data for 420,000 years, vol. Contribution Series \#2001076, NOAA/NGDC Paleoclimatology Program, 2001.

Plattner, G., Joos, F., Stocker, T., and Marchal, O.: Feedback mechanisms and sensitivities of ocean carbon uptake under global warming, Tellus B, 53, 564-592, 2001.

Proye, A. and Gattuso, J.-P.: seacarb, an R package to calculate parameters of the seawater carbonate system, http://cran.r-project. org/web/packages/seacarb/index.html, 2003.

R Development Core Team: R: A Language and Environment for 
Statistical Computing, R Foundation for Statistical Computing, Vienna, Austria, online available at: http://www.R-project.org, ISBN 3-900051-07-0, 2008.

Riebesell, U., Bellerby, R. G. J., Engel, A., Fabry, V. J., Hutchins, D. A., Reusch, T. B. H., Schulz, K. G., and Morel, F. M. M.: Comment on "Phytoplankton calcification in a high- $\mathrm{CO}_{2}$ world", Science, 322, 1466b-1466b, 2008.

Roy, R. N., Roy, L. N., Vogel, K. M., Porter-Moore, C., Pearson, T., Good, C. E., Millero, F. J., and Campbell, D. M.: The dissociation constants of carbonic acid in seawater at salinities 5 to 45 and temperatures 0 to $45^{\circ} \mathrm{C}$, Mar. Chem., 44, 249-267, 1993.

Sabine, C., Feely, R., Gruber, N., Key, R., Lee, K., Bullister, J., Wanninkhof, R., Wong, C., Wallace, D., Tilbrook, B., Millero, F., Peng, T., Kozyr, A., Ono, T., and Rios, A.: The oceanic sink for anthropogenic $\mathrm{CO}_{2}$, Science, 305(5682), 367-371, 2004.

Schneider, K. and Erez, J.: The effect of carbonate chemistry on calcification and photosynthesis in the hermatypic coral Acropora eurystoma, Limnol. Oceanogr., 51, 1284-1293, 2006.

Sciandra, A., Harlay, J., Lefèvre, D., Lemée, R., Rimmelin, P., Denis, M., and Gattuso, J.-P.: Response of the coccolithophorid Emiliania huxleyi to elevated partial pressure of $\mathrm{CO}_{2}$ under nitrate limitation, Mar. Ecol.-Prog. Ser., 261, 111-122, 2003.
Shi, D., Xu, Y., and Morel, F. M. M.: Effects of the $\mathrm{pH} / p \mathrm{CO}_{2}$ control method on medium chemistry and phytoplankton growth, Biogeosciences, 6, 1199-1207, 2009, http://www.biogeosciences.net/6/1199/2009/.

Smith, A. D. and Roth, A. A.: Effect of carbon dioxide concentration on calcification in the red coralline alga Bossiella orbigniana, Mar. Biol., 52, 217-225, 1979.

Swift, E. and Taylor, W. R.: The effect of $\mathrm{pH}$ on the division rate of the coccolithophorid Cricosphaera elongata, J. Phycol., 2, 121$125,1966$.

Trimborn, S., Langer, G., and Rost, B.: Effect of varying calcium concentrations and light intensities on calcification and photosynthesis in Emiliania huxleyi, Limnol. Oceanogr., 52, 22852293, 2007.

Wolf-Gladrow, D. A., Zeebe, R. E., Klaas, C., Körtzinger, A., and Dickson, A. G.: Total alkalinity: The explicit conservative expression and its application to biogeochemical processes, Mar. Chem., 106, 287-300, 2007.

Zeebe, R. E. and Wolf-Gladrow, D. A.: $\mathrm{CO}_{2}$ in seawater: equilibrium, kinetics, isotopes, Elsevier, Amsterdam, 2001. 